\title{
Design em tempos de insurgências
}

Luiz Lagares Izidio;

Rita Aparecida da Conceição Ribeiro

\section{resumo:}

Por meio da aproximação do design com o campo social o presente artigo propõe investigar novas associações entre design e práticas urbanas criativas na construção de espaços insurgentes de cidadania, de modo a ampliar e articular o pensamento projetual do design aos complexos desafios que a conjuntura sociopolítica contemporânea nos apresenta. Por meio de uma abordagem dialógica utiliza um referencial teórico que busca compreender a conjuntura sociopolítica na qual nós e o design estamos inseridos. A partir disso, estabelecemos uma relação entre design, cidadania, processos democráticos e práticas urbanas criativas, tornando possível propor futuros possíveis de atuação do design no âmbito da vida contemporânea.

\section{palaviras-chave:}

Design participativo, Design político, Espaços Insurgentes de Cidadania, 
A aproximação entre o design e o campo social acontece no momento em que consideramos o design um processo de interação social, pois, lida não apenas com objetos e sistemas abstratos, sendo assim é possível dizer que não existe uma neutralidade do design em relação às questões sociais.

Nessa perspectiva, o design é percebido como uma atividade criativa cujo objetivo é estabelecer as qualidades multifacetadas de objetos, processos, serviços e seus sistemas em ciclo completo de vida capaz de modificar o ambiente e transformar a relação dele com o indivíduo diante de suas necessidades concretas.

Dessa maneira, consideramos não ser possível que exista um design que não seja social, o que acontece é que muitas vezes o foco das abordagens tendem a ser mais mercadológico e financeiro. Podemos dizer então que a ação moderadora do design se estende para as esferas públicas e coletivas, e também para o modo como vivemos a complexa conjuntura sociopolítica contemporânea.

Portanto, pensar o design de forma ampla e inserido no contexto social faz com que ele se aproxime mais da realidade das pessoas, criando assim um ambiente material coerente para atender melhor as suas necessidades.

Nesse sentido, neste artigo propomos investigar novas associações entre design e práticas urbanas criativas na construção de espaços insurgentes de cidadania, ampliando e articulando o pensamento projetual do design aos complexos desafios que a conjuntura sociopolítica contemporânea nos apresenta.

Por meio de uma abordagem dialógica utilizamos um referencial teórico que busca compreender a conjuntura sociopolítica na qual nós e o design estamos inseridos. A partir disso, estabelecemos uma relação entre design, cidadania, processos democráticos e práticas urbanas criativas, tornando possível propor futuros possíveis de atuação do design no âmbito da vida contemporânea.

\section{0 processo social do design e a crise como possibilidade de insurgência}

Lidar com a conjuntura sociopolítica contemporânea é uma necessidade de todas as profissões e não apenas de nós, designers. $\mathrm{O}$ intuito de fazer essa abordagem é abranger as possibilidades de atuação, nesse campo, e não criar uma norma de como o designer deve agir no ato de projetar. A intenção é fomentar uma consciência crítica dos profissionais de design a fim de diminuir o desequilíbrio enorme entre os centros de poder e as pessoas submetidas a esses poderes. Isto porque o desequilíbrio é antidemocrático na medida em que nega o acesso, a participação e trata as pessoas como meras instâncias no processo de objetivação e mercantilização.

O design é uma atividade multidisciplinar, flexível e capaz de transformar realidades, uma de suas características é que suas práticas permitem mudanças constantes no desenvolvimento de projetos levando em consideração o problema tratado. Desse modo, é evidente o desafio de estabelecer novos paradigmas para a criação e utilização dos conhecimentos de design.

Em 2017, Manzini e Margolin, delinearam uma série de relações entre design e democracia, além de exprimir razões dessas aproximações, chamando a comunidade de design para se envolver na manutenção dos processos democráticos pelo mundo. Uma das aproximações propostas por Manzini e Margolin (2017) é o design como democracia, que segundo os autores, seria a prática do design participativo para que diversos atores possam moldar possibilidades, de se viver, que sejam mais justas e inclusivas. Esta visão reforça uma outra área de pesquisa em design que tem crescido que é a investigação da perspectiva política do design. O propósito é compreender quais as relações de poder estão envolvidas nos processos de design participativo e como o pensamento político pode estar presente na relação entre design e diversos outros campos do saber.

A conjuntura sociopolítica contemporânea mostra-nos um ambiente de crise que permeia todos os setores da sociedade transformando paisagens econômicas, políticas, sociais e culturais. Vivemos um tempo de emergência e esta se dá a partir do momento em que a história é atravessada por inúmeras temporalidades que estão emaranhadas e, por consequência, se afetam mutuamente colocando em crise as narrativas de progresso, acumulação e dos poderes constituídos.

Vivemos um tempo em que o capitalismo tem invadido nossas vidas capturando nossas subjetividades e nosso cognitivo envolvendo e abarcando até mesmo as formas de resistência criadas contra ele. Assim, pensar uma atuação política do design é colocá-lo no centro das discussões a respeito da busca de resistências micropolíticas ao capitalismo cognitivo (COCCO, 2014). Este termo, faz referência ao novo modo de apropriação de valor pelo capital sobre nossas vidas. $\mathrm{Na}$ 
contemporaneidade, o que gera valor são nossas ações cognitivas, afetivas, de comunicação e de conhecimento, ou seja, toda nossa produção imaterial que ao constituir o sentido, qualifica o processo de valorização dos bens. (COCCO, 2014).

O design ao lidar com os processos de interação social também está inserido nesse cenário. Essa não neutralidade sociopolítica tem impulsionado o campo de pesquisa do design criando uma desterritorialização da produção científica e do próprio fazer do design, abrindo possibilidades de compartilhamento entre saberes e fazeres, formais e informais, e em geral, de confluências entre diferentes atores sociais.

Nesse sentido um momento de crise pode ser visto como brecha para a resistência, além de fortalecer o papel sociopolítico do design. Além de ser uma possibilidade de construção de futuros possíveis para o design a partir da compreensão da crise como um dissenso, ou seja, uma ruptura e uma descontinuidade sobre algo que é imposto.

As revoluções, assim como as crises, não têm princípio e fim definidos, são eventos que passam por um período liminar, momento ambíguo em que convivem simultaneamente as ideias hegemônicas estabelecidas e o ideário de resistência.

O cenário global de crise que estamos vivendo abrange muitos aspectos da sociedade e ameaça direitos e conquistas que tínhamos como garantidos. No entanto, é preciso pensar para além do problema e buscar alternativas a este momento.

Sobre o processo de crise, Deleuze; Guattari (1995) entendem a crise como um sistema complexo, cuja compreensão perpassa pelo entendimento da não separação dos âmbitos políticos, ambientais e subjetivos das nossas ações no mundo.

Esses autores veem a crise como um ponto de aglutinação e de saturação onde algo se rompe, sendo possível a partir de então criarmos novos traçados. Um dos legados de Deleuze e Guattari para nós, é pensar a crise pela crítica e clínica, ou seja, enxergar a crise em sua ambiguidade, uma mudança, forçada, repentina, inesperada e até mesmo violenta, mas que nos força a pensar (DELEUZE; GUATTARI, 1995). As crises surgem como um momento de desestabilizarmos os processos instituídos criando movimentos de transformação que irão modificar as formas de ser, viver e habitar o mundo.

A análise da relação entre esses movimentos de mudança e os processos instituídos é o que Guattari e Rolnik (2000) chama de micropolítica, ou seja, é a busca por apreender o movimento das coisas, esse movimento é feito pelos corpos, poderes e lutas que estão num mundo e constituem esse mundo. Portanto a micropolítica está interessada em como as relações desses movimentos de mudança acontecem, criam corpos mais complexos e coletivos (GUATTARI; ROLNIK, 2000). Além da micropolítica, os autores, falam sobre os Universos de Referência, que são coordenadas conjunturais de onde os corpos se orientam. Por isso, a importância de pensarmos diferentes Universos de Referência que convivam e se relacionem. Portanto, como podemos transformar não só nossa política, mas transformar nossos universos referenciais sobre o que olhamos ou para onde olhamos quando pensamos em política. O que consideramos político? Como construir relações, vivências e experimentações políticas por meio do design?

A crise torna-se, portanto, um momento importante para agirmos de forma micropolítica para mudança de foco, no que diz respeito à construção do papel social e político do design na e para a sociedade. É um momento importante para pensarmos as relações de poder instituídas na interação da sociedade, para que possamos engajar em práticas de mudança e não só em simples manutenção dos processos instituídos.

Para Pelbart (2011), essa captura do desejo coletivo, pelo capital, contribui para a manutenção das relações de poder instituído. Sendo assim é imperativo pensarmos a relação entre o capital e nossos desejos e de que forma essa relação pode estabelecer a permanência desses processos instituídos ou a mudança dessa relação (PELBART, 2011).

Para tanto, faz-se necessário entender o que cabe ao design nesse processo complexo e como os engendramentos existentes nesse dissenso interferem diretamente nas ações criativas e na formação de uma imaginação viva (comum) de resistência a crise. O que já conseguimos perceber é que ações mais democráticas de fazer design tornam-se um horizonte possível para o fortalecimento do papel social, político e resistência ao capitalismo cognitivo. 
No entanto é preciso criar estratégias que permitam que o design seja um agente constituinte de espaços de subjetividades ativas para a solução desses problemas complexos e futuros possíveis e desejáveis.

\section{Design político}

As crises vividas pelo capitalismo, desde 1929, com a quebra da bolsa de Nova York, vêm sendo globalizadas e têm gerado consequências devastadoras, populações endividadas, dívidas impagáveis, recessão econômica e insegurança social. As lutas contemporâneas são de certa forma uma recusa às abstrações do estado de violência econômico e ideológico, vigentes no poder instituído.

Esses movimentos multitudinários fizeram com que os indignados passassem a ocupar as ruas, as redes, praças e prédios públicos, esses movimentos provocam uma desestabilização dos consensos e poderes constituídos, ou seja, surgem como uma emergência da mudança. De forma geral estes movimentos demandavam por democracia direta, por meios mais horizontais de tomada de decisão para problemas da cidade como moradia, transporte, violência urbana/policial, urbanismo higienista entre outros.

É a partir dessa urgência por uma resistência, que emerge a necessidade da produção do comum, de novas formas de vida e de relações sociais que tenham como base a nossa capacidade de nos inventar e nos reinventar permanentemente. Diante disso, nos vemos imersos em uma dinâmica que se movimenta em torno de uma saída da impotência gerada pelas velhas instituições da soberania e da busca de um pensamento comum que nos leve em direção a exercícios de reinvenção das relações produtivas, dos modos de convivência e dos hábitos democráticos.

Do ponto de vista da resistência, portanto, a saída da crise estaria na capacidade de intensificarmos aquela força-criativa capaz de produzir novas tecnologias do comum, de alavancar processos de diferenciação, produção de subjetividade (interação social, cooperação, linguagem, informação, saberes e afetos). É essa força criativa que faz com que seja possível criar novas relações e define uma "estética da existência" ou seja a construção de um comum (PELBART, 2011).

$\mathrm{O}$ design se conecta a essa produção do comum como um agente gerador e potencializador dessa força criativa, utilizando a interação social como ferramenta, indo além da simples relação entre homem e coisas, mas como um dispositivo ágil de subjetivação capaz de perceber as singularidades dos indivíduos. Nesse contexto observamos que novas vias de empenho político e social do design alinhadas a capacidade autônoma, dos indivíduos e comunidades, de se comunicarem e se organizarem têm sido descobertas, são ações que vão além do alcance dos métodos usuais de controle empresarial e da política oficial.

Ainda que precarizados, os novos agentes de resistência organizam-se não somente para expor e conter os engendramentos do capitalismo e da política instituída, mas se unem em colaboração e cocriação, para efetivamente criar alternativas produtivas a este estado dramático de exploração, injustiça e aniquilação das riquezas comuns que o Império nos impõe.

Como exemplos desses novos agentes, que ligam produção de subjetividade, resistência e renovação política, podemos citar ações de design participativo. Essas ações formam uma rede de produção simbólica, são movimentos relacionados com o design e artesanato, design e softwares livres, design e agricultura comunitária, design e ocupações populares, design e coletivos de arte ativismo, design e luta pela democracia, design e meio ambiente, etc.

Muitas dessas iniciativas se interessam pelo processo de formação de um pensamento político do design, além de possuírem um pensamento de produção em comum. Elas permitem a emergência não somente de percepções e sensibilidades, mas de relações e expectativas, aproximando pessoas, conectando outras redes e efetivando os elos imprescindíveis para a superação da ansiedade e imobilização coletiva. Benjamin (1994) considera ser fundamental pensarmos os meios de produção na constituição de uma forma política. Assim, como já dito anteriormente, os meios de produção e de criação, agora, foram cooptados pelo capitalismo cognitivo, que por sua vez valoriza o pensamento e a produção vinda da subjetividade e criatividade dos indivíduos.

Nesse sentido podemos dizer que os meios de produção, hoje, não estão mais só nas fábricas, mas envolvem, também ou principalmente, o pensamento que se desenvolve no momento de concepção dos produtos. Ou seja, os indivíduos passam a ter centralidade na produção, e consequentemente, sua produção torna-se política, uma vez que a prática política só é possível no embate entre o sujeito e o que está diante dele. A constituição de um pensamento sobre o papel 
sociopolítico do design abre espaço para a intervenção e mudanças pelos sujeitos para a construção de um design político.

Muitos projetos de design, principalmente, denominados sociais são construídos a partir da utopia de uma ação política do design, porém, na realidade, são cooptados e reproduzem os mesmos mecanismos de dominação presentes nos processos instituídos do capital. Ainda é inviável (ou talvez nunca seja possível) verificar, pelo viés qualitativo, o nível de mudança social por meio de ações políticas de design, uma vez que essas, acontecem nas subjetividades como micropolíticas. As ações micropolíticas ainda agem, de forma lenta, porém podem sim produzir mudanças no nível macropolítico.

Acreditamos que os processos democráticos do design são ações que ainda estão no nível micropolítico, mas que podem vir a dar resultados macropolíticos. Pois são práticas construídas com base na teoria democrática - participação, igualdade, legitimidade, autogoverno, dissenso e liberdades - perpassando pela compreensão das formas de expressão contemporâneas, pela produção dos afetos e subjetividades, de como os dissensos se manifestam, e de como os indivíduos podem ocupar a cena pública, construindo assim política na prática do dia a dia.

A criação desses dispositivos perpassa pelo caráter democrático do design, ou seja, formas de ação que possibilitem de fato a horizontalidade na tomada de decisão, a reconfiguração do lugar de poder e maneiras democráticas de projetar. Mouffe (2006) ao propor um modelo democrático agonístico vislumbra uma ordem democrática capaz de assumir o dissenso não como um antagonista, mas como um agente capaz de auxiliar a construção de uma prática democrática mais real.

No que diz respeito ao design é o dissenso que torna as suas práticas sociais ricas em criatividade, inovação e possibilidades de construção de futuros possíveis no tempo presente. $\mathrm{O}$ dissenso é algo inerente ao pensamento político do design e coloca as práticas democráticas de design como micropolíticas em relação ao capitalismo cognitivo. Dessa forma o design age de forma biopolítica, ressignificando o poder que age sobre nossas vidas em potência de vida, ou seja, cria mecanismos de resistências aos processos instituídos. (PELBART, 2011).

Nessa linha de pensamento, retomamos aqui a percepção de Manzini; Margolin (2017) como uma possibilidade de futuro possível para o design, pois os autores aproximam o design à democracia, na perspectiva da prática do design participativo como recurso para que diversos atores possam moldar novos mundos presentes e futuros de maneira justa e inclusiva.

Um exemplo disso são iniciativas sociais onde o design está incluído como um agente potencializador da criatividade alavancando processos de diferenciação, produção de subjetividade (interação social, cooperação, linguagem, informação, saberes e afetos), que aqui tratamos como sendo as práticas urbanas criativas. Geralmente as práticas urbanas criativas estão inseridas no contexto das cidades em locais onde o poder do capital exerce grande influencia sobre as vidas existentes ali.

Pensar o design dentro desses espaços como um agente capaz de ressignificar as ações cognitivas das pessoas possibilita uma transformação do poder que subjuga para uma potência de vida e de criatividade, isto faz com que estes espaços se tornem lugares onde a cidadania possa ser exercida de maneira efetiva. Essa aproximação requer um posicionamento político, tanto da própria área de conhecimento do design, como dos profissionais que exercem suas práticas em busca de maneiras ativas para a manutenção de processos democráticos por meio de ações que envolvam a teoria e a prática do design.

\section{Espaços de cidadania insurgente}

A construção dos espaços de cidadania insurgentes passa pela reconfiguração do que chamamos de espaço social da cidade. Segundo Lefebvre (2008) o espaço social não se constitui a partir de uma teorização, mas sim por meio da prática do dia a dia e do cotidiano. Nele está contida a divisão social do trabalho, portanto, ele é o lugar onde os objetos são construídos, o conjunto das coisas que ocupam a cidade e de seus subconjuntos. (LEFEBVRE, 2008).

Este "lugar" é o que o autor James Holston (2013) considera como sendo os espaços de cidadania insurgentes. $\mathrm{O}$ autor utiliza o termo insurgentes para enfatizar a oposição desses espaços de cidadania aos espaços modernistas que ainda dominam fisicamente tantas cidades. Além disso, o termo é utilizado também em oposição ao projeto político modernista que absorve a cidadania num plano de construção do Estado, mas, que no processo tende a reforçar um projeto elitista de contenção das classes trabalhadoras. Adotaremos esse termo para referirmos as novas e/ou outras fontes de 
cidadania e à afirmação de sua legitimidade, pois esses espaços constituem novas formas metropolitanas do social, ainda não absorvidas nas velhas estruturas e nem por elas liquidadas (HOLSTON, 2013).

Portanto, repensar a construção do espaço social diz respeito a desenvolver uma imaginação social que inclua as pessoas e suas potências criativas, como agentes ativos no processo de construção de soluções para os problemas relacionados a cidade. No que diz respeito as práticas urbanas criativas, onde a prática do design participativo está presente, normalmente percebemos que há um reposicionamento do cidadão como protagonista, como agente criativo, agente construtor de soluções e como alguém que consegue exercer sua cidadania.

Já que estamos falando em imaginação e projetando, esta, para um tempo futuro, no intuito de conduzir possibilidades de atuação cidadã por meio do design na cidade, vale a pena dispormos de um tempo para pensarmos o que seria imaginar o futuro? Além disso, pensarmos de que cidadania estamos falando? E qual a relação desse futuro imaginado por uma participação cidadã com o design?

A imaginação do futuro não é feita do nada. Para pensar e imaginar o futuro é preciso uma reflexão e análise das condições prévias do quadro ou conjuntura atual, de maneira que seja possível antecipar problemas no processo. De certa maneira essa antecipação pode ser considerada um prognóstico da atualidade sendo peça fundamental para se planejar ações futuras. Para tanto é necessário que a ideia do prognóstico seja vista de maneira flexível e não-formalista, sendo mais direcionada para a ideia de cenários.

O conceito de cenários é visto aqui como um exercício de simulação no qual são imaginados desdobramentos possíveis para a atuação cidadã e do design na solução de problemas dentro do ambiente da cidade. Nesse sentido não pretendemos quantificar propriedades e nem esgotar as possíveis trajetórias de ações que envolvam a participação cidadã, design e cidade. O desafio é exatamente não fazer prognósticos que sejam reducionistas e sim processos abertos para construção coletiva e colaborativa.

Dessa maneira, acreditamos que a fonte desses cenários futuros não esteja em nenhuma produção específica de design, mas sim no desenvolvimento de um espaço em que diversas áreas possam contribuir, um espaço interdisciplinar, onde as possibilidades de atuação na cidade possam conviver.

Ainda para compreendermos o surgimento dos espaços de cidadania insurgente é importante atentarmos para o processo de cooptação da cidade pelo capitalismo neoliberal, no intuito de homogeneizar os espaços, incluindo até mesmo os espaços criativos da cidade. No cenário da cidade neoliberal onde o Estado regulamenta todo uso do espaço, a gestão e o planejamento urbano tendem a ser utilizados como engrenagens para o funcionamento de uma cidade empresa. A crítica que fazemos é que essas ferramentas não admitem e nem desenvolvem produtivamente os paradoxos de um futuro imaginado. Ao invés disso elas são utilizadas para tentar a construção de um plano sem contradições e sem conflito. O conflito é algo importante para o universo da cidade, pois é no dissenso que podemos enxergar o outro e perceber suas diferenças e esse processo tem relação direta com a cidadania. (RENA; BRUZZI, 2014).

A cidadania formal refere-se à condição de membros de uma comunidade política na história moderna, predominantemente o Estado-nação. A cidadania substantiva diz respeito à série de direitos civis, políticos e sociais disponíveis ao povo. A perspectiva de cidadania muda à medida que novos membros surgem para manifestar suas reivindicações, expandindo seu alcance. Por isso, pensarmos maneiras mais democráticas de exercer o design participativo dentro de práticas urbanas criativas é uma maneira de potencializar o exercício da cidadania. Marshall (1977) considera que "Cidadania é um status conferido a quem é membro pleno de uma comunidade. Todos que o possuem são iguais em relação aos direitos e deveres que a esse status são atribuídos". (MARSHALL, 1977, p.92).

O autor ainda salienta que é a percepção direta da condição de membro da comunidade com base na lealdade a uma civilização, que é um bem comum, que faz com que os indivíduos exerçam sua cidadania o que garante uma participação direta e assegura os direitos e responsabilidades. (MARSHALL, 1977, p.92). Por isso que o protagonismo da comunidade onde o design está inserido em uma prática urbana criativa é tão importante, pois ele favorece o reconhecimento do indivíduo como parte integrante do grupo e o reposiciona no que diz respeito aos seus direitos e responsabilidades para com a sociedade. 
A insurgência, ou seja, o "agir contra" uma determinada ordem é importante para o projeto de repensar o social, porque revela um domínio do possível que está enraizado na heterogeneidade da experiência vivida, isto é, está ligada a um presente real e não em futuros utópicos.

O paradoxo é que a construção de cenários futuros para a participação cidadã precisa envolver não só o desenvolvimento das formas insurgentes do social, mas também os recursos do Estado para definir, e ocasionalmente impor, uma concepção mais abrangente de direito do que, às vezes, é possível encontrar no nível local.

\section{0 design como agente potencializador de espaços de cidadania insurgente}

O design é uma atividade criativa cujo um dos objetivos é constituir relações entre as pessoas e os objetos, os processos e os serviços, agindo como um agente facilitador entre aspectos tecnológicos, econômicos e culturais. Sendo capaz de usar a criatividade para moldar o ambiente diante de suas mudanças, portanto, a criatividade é um aspecto inerente ao design. Por isso, podemos considerar uma relação clara entre o design e potência criativa existente nas práticas urbanas criativas.

A criatividade é a faculdade que nos permite pensar em nós mesmos de forma diferente do que somos e, portanto, propor uma finalidade além da situação presente. Sem criatividade pode haver cálculo, mas não projeto. O projeto é a predisposição dos meios operacionais para pôr em prática os processos criativos. O design é o agente que, dentro de práticas urbanas criativas, possibilita o uso de ferramentas, métodos e metodologias fomentando a criatividade e inovação entre os cidadãos participantes dessas práticas. Seus meios criativos quando utilizados de forma ética e inseridos no contexto social, aproximariam as pessoas da realidade, criando um ambiente material e imaterial coerente para atender melhor às necessidades dos projetos nos quais o design está inserido.

Um exemplo exitoso dessa relação entre o design inserido em práticas urbanas criativas é a colaboração entre o CERNE ${ }^{1}$ e o Centro Cultural Lá da Favelinha ${ }^{2}$ na produção de moda sustentável. O programa de extensão universitária CERNE vem trabalhando em colaboração com o idealizador criativo do Lá da Favelinha, Kdu dos Anjos e com as costureiras do Aglomerado da Serra (periferia de Belo Horizonte), no desenvolvimento e produção das coleções da Remexe, marca de roupa do centro cultural. As coleções têm sido produzidas a partir da ação de upcycling ${ }^{3}$ na moda, ressignificando doações de resíduos de tecidos em roupas e acessórios.

O programa trabalha a partir da ideia de inovação socioambiental e integração entre metodologias criativas e técnicas produtivas, visando o benefício social, ambiental, cultural, econômico e buscando atender as demandas da associação Lá da favelinha. A proposta metodológica é baseada no pensamento sistêmico aplicado ao Design Social, integrando o planejamento da cadeia produtiva, prestação de serviço, projetos e produtos, ao mesmo tempo em que acontece o mapeamento de matérias-primas, fornecedores, usuários e o descarte ambientalmente amigáveis. Portanto, a lógica do sistema de serviço do produto é fundamental para compreender os conceitos metodológicos utilizados pelo grupo. (RIBEIRO; MAZZIEIRO; WENDLING, 2019)

A partir desses conceitos foram propostas oficinas de criação e desenvolvimento da coleção intitulada É Curva. Todas essas oficinas foram realizadas de maneira colaborativa e cocriativa, entre estudantes bolsistas do programa de extensão e os beneficiários da associação Lá da favelinha.

\footnotetext{
${ }^{1} \mathrm{O}$ projeto CERNE é um trabalho de educação em sustentabilidade ambiental e social, aliado à capacitação em design sustentável. O objetivo é a formação da consciência social, ambiental e cultural dos beneficiários do projeto, assim como dos estudantes da universidade, a partir da noção de reaproveitamento dos resíduos industriais.
}

${ }^{2}$ O Centro Cultural Lá da Favelinha é uma iniciativa da comunidade do Aglomerado da Serra em Belo Horizonte. Fundado em janeiro de 2015, o projeto nasceu a partir de uma oficina de rap que acontecia no aglomerado. Com o crescimento da oficina que, logo após, se tornou também uma biblioteca, surgia a demanda de haver mais atividades que promovessem a cultura nos entornos da comunidade. O Centro cultural possui vários apoiadores, um deles é a Universidade FUMEC, que atuam por meio de projetos de extensão.

${ }^{3}$ O Upcycling/recriutilização, também conhecido como reutilização criativa, é o processo de transformação subprodutos, resíduos, produtos inúteis ou indesejados em novos materiais ou produtos de melhor qualidade ou com maior valor ambiental. 
Figura 01: Coleção É Curva, coleção da marca Remexe Lá da Favelinha.

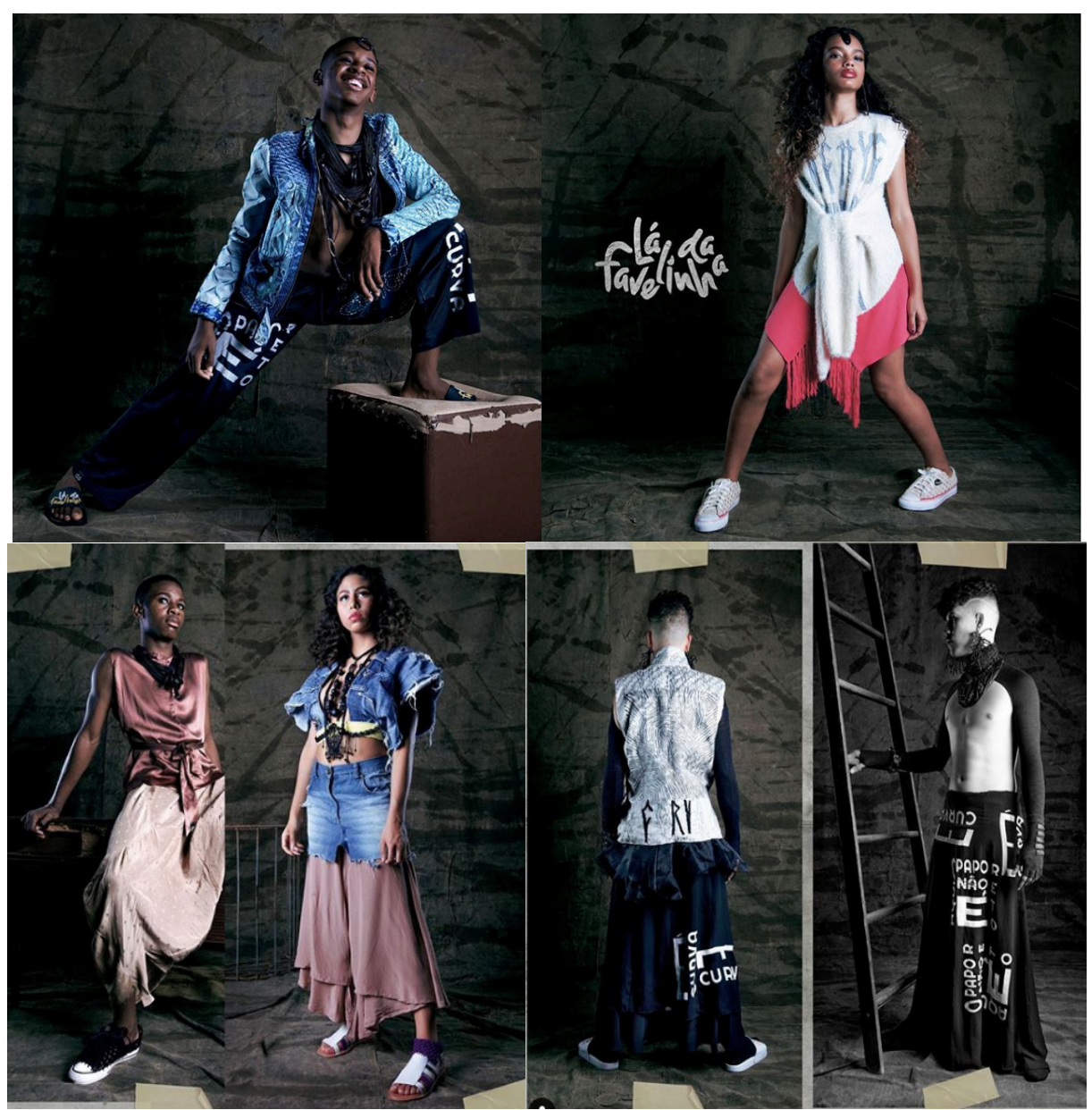

Fonte: Instagram Remexe Lá da Favelinha

O resultado são roupas criadas a partir da ressignificação da criatividade dos participantes do projeto, signos, modos de vida e potencialidades do território dos moradores do Aglomerado da Serra. Além dos resultados visíveis nos produtos, outros ganhos foram percebidos, como soluções sistêmicas para situações específicas do projeto, criadas a partir da cocriação entre universidade e comunidade, desenvolvimento da autonomia criativa dos beneficiários, principalmente na resolução de problemas do dia a dia, além de possibilidade de integração dos conhecimentos de áreas diferentes.

É possível dizer que os métodos do design foram utilizadas em prol da ampliação do repertório cultural e criativo dos beneficiários, acerca do seu próprio território, ampliando, assim, a maneira como estes se veem no espaço urbano e impactando diretamente na construção do imaginário social que cerca todo o universo criativo associado ao ambiente da cidade.

\section{Algumas considerações}

Entendemos práticas urbanas criativas como sendo "maneiras de fazer" que intervêm na distribuição geral de como os indivíduos se relacionam e criam novos modos de ser. Nesse sentido, torna-se claro a habilidade do design a respeito da potencialização do processo criativo de pessoas beneficiárias dessas práticas.

Vimos que é possível o design se envolver em práticas urbanas criativas e potencializar o surgimento de espaços de cidadania insurgentes, pois, por meio de seus métodos alavancam-se os processos de diferenciação, produção de subjetividade, cooperação, saberes e afetos, como acontece na parceria entre o CERNE e o Lá da Favelinha. 
Geralmente, quando a prática do design participativo está presente, os resultados trazem à tona interações oriundas de afetividade, subjetividades e valorização da vida dos beneficiários, tornando este processo biopotente, pois, ressignifica o poder que subjuga suas vidas em poder de vida, potência de criação e sobrevivência, tornando o ato de criação um exercício de insurgência no cotidiano.

Os produtos da coleção refletem as potencialidades de linguagem, informação, interação social e criativa dos beneficiários, tornando-os agentes de transformação de si mesmos, na medida em que cocriam alternativas produtivas ao estado de exploração de seu território pelo capital.

O caráter participativo e colaborativo é de suma importância, pois prevê processos democráticos de inclusão dos sujeitos presentes no processo de criação, redirecionando o protagonismo das ações para a comunidade, fortalecendo assim os aspectos de cidadania e a autonomia.

Nesse sentido, o design utiliza a estética da existência como força motriz para potencializar a criatividade projetando um espaço de cidadania insurgente, ou seja, um lugar onde a valorização do indivíduo acontece em sua completude (aspectos sociais, políticos, emocionais e subjetivos), incluindo-o como agente de transformação do seu "lugar" proporcionando que ele exerça sua cidadania.

\section{Design in times of insurgencies}

\section{Abstract:}

Through the approximation of design with the social field, this article proposes to investigate new associations between design and creative urban practices in the construction of insurgent spaces of citizenship, in order to expand and articulate the design thinking of design to the complex challenges that the contemporary socio-political conjuncture introduces us. Through a dialogical approach, it uses a theoretical framework that seeks to understand the socio-political context in which we and design are inserted. Based on this, we established a relationship between design, citizenship, democratic processes and creative urban practices, making it possible to propose possible futures for the performance of design in the context of contemporary life.

\section{Keywords:}

Participatory design; Political design; Insurgent Citizenship Spaces

\section{Referências bibliográficas}

BENJAMIN, Walter. Obras Escolhidas, Vol. 1 - Magia e Técnica, Arte e Política. São Paulo: Brasiliense. 1994.

COCCO, Giuseppe. Korpobraz: por uma política dos corpos. Rio de Janeiro: Mauad. 2014.

DELEUZE. G.; GUATTARI, F. Mil platôs: capitalismo e esquizofrenia; tradução Ana Lúcia de Oliveira e Lúcia Cláudia Leão - São Paulo, Editora 34, 1995, v.2

GUATTARI, Félix; ROLNIK, Suely. Micropolítica: cartografias do desejo. Petrópolis: Editora Vozes, 6.Ed. 2000.isp:

HOLSTON, James. Cidadania insurgente: disjunções da democracia e da modernidade no Brasil / James Holston ; tradução Claudio Carina ; revisão técnica Luísa Valentini. - 1a ed. - São Paulo : Companhia das Letras, 2013.

LEFEBVRE, Henri. Espaço e política / Henri Lefebvre; Tradução Margarida Maria de Andrade e Sérgio Martins - Belo Horizonte: Editora UFMG, 2008. 
MANZINI, Ezio. Design para a inovação social e sustentabilidade: comunidades criativas, organizações colaborativas e novas redes projetuais. [coordenação de tradução Carla Cipolla; equipe Elisa Spampinato, Aline Lys Silva]. Rio de Janeiro: E-papers, 2008.

MANZINI, Ezio; MARGOLIN, Victor. Open Letter to the Design Community: Stand Up for Democracy. Disponível em http://www.desisnetwork.org/2017/04/11/open-letter/ acessado em 05/2017:

MARSHALL, T. H. Cidadania, classe social e status. Rio de Janeiro: Zahar, 1977.

MOUFFE, Chantal. Por um modelo agonístico de democracia. Revista de sociologia e política, № 25, Curitiba, 25, p. 165-175, jun. 2006.

PELBART, Peter Pál. Vida capital: ensaios de biopolítica/ Peter Pál Pelbert. [1 a e 2 areimpr.] São Paulo: Iluminuras, 2011.

RENA, Natacha; BRUZZI, Paula. Processos criativos biopotentes constituindo novas possibilidades de constituição do comum no território urbano. In. Lugar Comum - Estudos de Mídia, Cultura e Democracia. Universidade Federal do Rio de Janeiro. Laboratório Território e Comunicação LABTeC/ESS/UFRJ - Vol I, n. I (1997) - Rio de janeiro: UFR, n. 43 - maio-ago, 2014

RIBEIRO, Juliana pontes; MAZZIEIRO, Adriana Tonani; WENDLING, Gabriel Julian. Cerne Project and Remexe Collection: actions in social design in search of social innovations of systemic character. Designing Sustainability for All. In Volume 5: Design for social equity, inclusion and cohesion, p. 454-458. 2019. 